\title{
The effect of occupational stress, psychological stress and burnout on employee performance: Evidence from banking industry
}

\author{
Shahram Hashemnia, Somayeh Abadiyan* and Behnam Ghorbani Fard
}

Management Group, Payam Noor University, Tehran, Iran

CHRON I C L E A B S T R A C T

Article history:

Received March 202014

Accepted 28 July 2014

Available online

August 62014

Keywords:

Occupational stress

Psychological stress

Burnout

Employee performance

Occupational stress

Interpersonal performance

Organizational performance

\section{Introduction}

During the past few decades, there have been tremendous evidences that the productivity of any firm depends on lower level of employees' burnout and stress at workplace (Khan \& Zafar, 2013; Rahman, 2013). Al-Kahtani and Saad (2013) investigated the effect of some certain demographical variables such as position in the current job, age, experience and marital status on job burnout among selected banking employees in Saudi Arabia. In their survey, Job Burnout Inventory developed by Maslach and Jackson (1981) and biographical information blank were used to perform the survey. They reported that subordinate staff, married and high experienced group of employees reflected higher degree of job burnout. In addition, the younger and older bank employees were detected to differ substantially in terms of job burnout.

*Corresponding author.

E-mail addresses: somayeh.abadiyan@gmail.com (S. Abadiyan) 
According to Bashir and Ramay (2010), bankers are under a big pressure because of antecedents of stress such as Overload, Role ambiguity, Role conflict, Responsibility for people, Participation, Lack of feedback, Keeping up with rapid technological change. Therefore, one of the affected outcomes of stress is on job performance.

Bashir and Ramay (2010) performed a survey among some employees who work for banking industry in Pakistan and reported a negative correlation between job stress and job performances and job stress significantly could reduce the performance of an individual. The results recommended that organization should facilitate supportive culture within the working atmosphere of the organization. Arzu (2011) determined whether bank employees' burnout levels and satisfaction of life differentiate significantly according to certain variables. Khattak et al. (2011) also reported similar results.

Chou et al. (2014) explored the prevalence and associated factors of burnout among five medical professions in a regional teaching hospital. They concluded that physician assistant was an emerging high burnout group; its severity was similar to that of nurses and far more than that of physicians, administrative staff and medical technicians. Jamal (2011) examined the role of organizational commitment in the relationship between job stress and job performance among some selected employees who were working for some large US firms operating in Malaysia and Pakistan. They reported some negative relationship between stress and performance in both countries.

\section{The proposed method}

This paper presents an empirical investigation on the effects of occupational stress, psychological stress as well as job burnout on women's employee performance in city of Karaj, Iran. The proposed study designs a questionnaire in Likert scale and distributes it among all female employees who worked for Bank Maskan in this city. In our survey, employee performance consists of three parts of interpersonal performance, job performance as well as organizational performance. Fig. 1 demonstrates the structure of the proposed study.

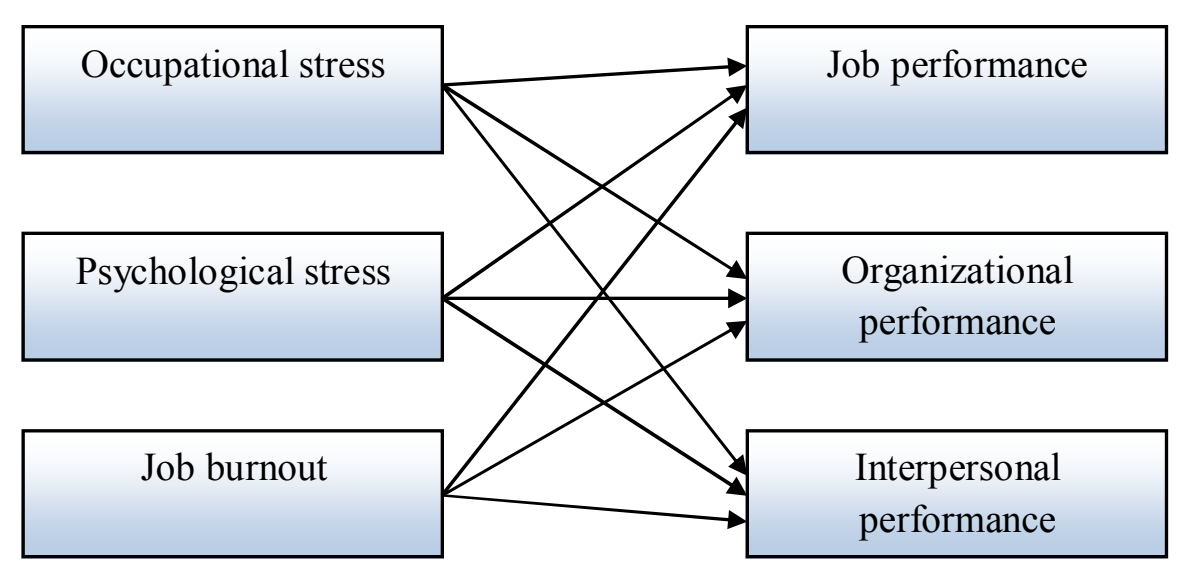

Fig. 1. The proposed method

Based on the structure of the proposed study given in Fig. 1, the following nine hypotheses are stated.

1. Occupational stress influences on job performance.

2. Psychological stress influences on job performance.

3. Job burnout influences on job performance.

4. Occupational stress influences on organizational performance.

5. Psychological stress influences on organizational performance. 
6. Job burnout influences on organizational performance.

7. Occupational stress influences on interpersonal performance.

8. Psychological stress influences on interpersonal performance.

9. Job burnout influences on interpersonal performance.

The proposed study designs a questionnaire in Likert scale and first invites some expert to verify the overall content of the questionnaire and after confirming the questionnaire, distributes it among some limit number of employees. Table 1 summarizes Cronbach alphas for all six components.

Table 1

Cronbach alpha for six components of the survey

\begin{tabular}{lcccccc}
\hline & \multicolumn{3}{c}{ Stress } & \multicolumn{3}{c}{ Performance } \\
\cline { 2 - 7 } Variable & Occupational & Psychological & Job burnout & Job & Organizational & Interpersonal \\
\hline Alpha & 0.77 & 0.70 & 0.74 & 0.77 & 0.84 & 0.70 \\
\hline
\end{tabular}

As we can observe from the results of Table 1, all components of the survey maintain desirable value, which are within acceptable limit. Therefore, we may confirm the questionnaire. Fig. 2 shows some personal characteristics of the participants.

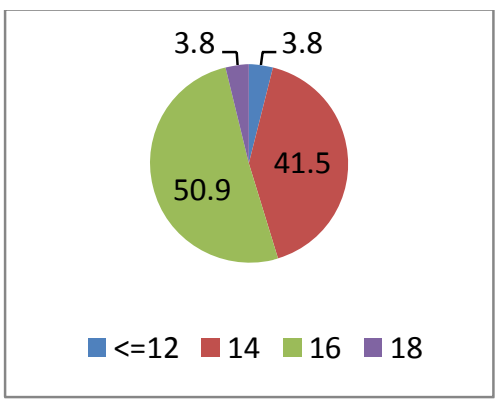

Years of education

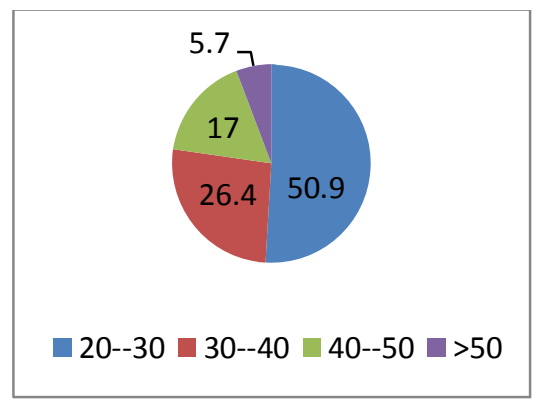

Age

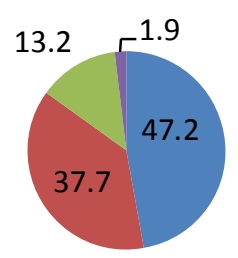

$\square<5 \square 5--15 \square 15--25 \square>=25$

Years of job experiences

Fig. 2. Personal characteristics of the participants

As we can observe from the results of Fig. 2, all participants were middle-aged people, mostly with some university education and good job experiences. The implementation of Kolmogorov-Smirnov test has indicated that the data were not normally distributed. Therefore, we use Spearman correlation tests to verify the hypotheses of the survey.

\section{The results}

In this section, we present details of our findings on testing various hypotheses of the survey. We first present the results of the implementation of Spearman correlation among various pairs of survey and the results are summarized in Table 2 as follows,

Table 2

The summary of Spearman correlation

\begin{tabular}{|c|c|c|c|c|c|c|c|}
\hline Row & & 1 & 2 & 3 & 4 & 5 & 6 \\
\hline 1 & Job Burnout & 1 & & & & & \\
\hline 2 & Occupational stress & $0.68^{* *}$ & 1 & & & & \\
\hline 3 & Psychological stress & $0.80^{* *}$ & $0.62^{* *}$ & 1 & & & \\
\hline 4 & Organizational & $0.74^{* *}$ & $0.72^{* *}$ & $0.84^{* *}$ & 1 & & \\
\hline 5 & Job performance & $0.57^{* *}$ & $0.56^{* *}$ & $0.59^{* *}$ & $0.82^{* *}$ & 1 & \\
\hline 6 & Interpersonal performance & $0.84^{* *}$ & $0.70^{* *}$ & $0.91^{* *}$ & $0.84^{* *}$ & $0.61^{* *}$ & 1 \\
\hline
\end{tabular}


As we can observe from the results of Table 2, there seems to be some positive and meaningful relationships between different components of the survey. Table 3 demonstrates the summary of testing various hypotheses.

\section{Table 3}

The summary of the results of testing nine hypotheses using Spearman correlation test

\begin{tabular}{lcccccccccc}
\hline Hypothesis & 1 & 2 & 3 & 4 & 5 & 6 & 7 & 8 & 9 \\
\hline Correlation & 0.56 & 0.59 & 0.57 & 0.72 & 0.84 & 0.74 & 0.70 & 0.91 & 0.84 \\
Sig. & 0.00 & 0.00 & 0.00 & 0.00 & 0.00 & 0.00 & 0.00 & 0.00 & 0.00 \\
Result & Confirmed & Confirmed & Confirmed & Confirmed & Confirmed & Confirmed & Confirmed & Confirmed & Confirmed \\
\hline
\end{tabular}

Based on the results of Table 3, the highest positive correlation belongs to hypothesis number eighth, which implies psychological stress influences on interpersonal performance. In addition, it seems to be psychological stress influences strongly on organizational performance as well as interpersonal performance.

\subsection{The effect of job performance}

We now present the results of our survey on testing the hypothesis of the survey based on stepwise regression technique. The implementation of the stepwise regression has yielded the results given in Eq. (1) as follows,

Job Performance $=1.253+0.691$ Psychological stress

t-value $\quad 2.459 \quad 5.841$

Sig. $\quad 0.017 \quad 0.000 \quad \bar{R}^{2}=0.389$

Based on the results of Eq. (1), psychological stress influences positively on job performance. The result of t-student indicates that the effect is statistically significant and adjusted R-Square indicates that regression model states that psychological stress approximately describes $39 \%$ of the changes on job performance.

\subsection{The effect of organizational performance}

We now investigate the effects of different stresses on organizational performance. The implementation of the stepwise regression has yielded the results given in Eq. (2) as follows,

Organizational Performance $=0.411+0.552$ Psychological stress +0.349 Occupational stress
t-value
1.630
7.751
4.952
Sig.
$0 .{ }^{\circ} 09 \quad 0.000$
$0.000 \quad \bar{R}^{2}=0.818$

Based on the results of Eq. (2), psychological and occupational stresses maintain positive impact on job performance. The result of t-student indicates that the effects are statistically significant and adjusted R-Square indicates that regression model states that psychological and occupational stresses approximately describe $82 \%$ of the changes on organizational performance.

\subsection{The effect of interpersonal performance}

Finally, we study the impacts of various stresses on individual performance. The implementation of the stepwise regression has yielded the results given in Eq. (3) as follows, 
Interpersonal Performance $=0.648+0.644$ Psychological stress +0.217 Occupational stress

t-value

12.136

0.001

0.000
4.128

$0.000 \quad \bar{R}^{2}=0.855$

Based on the results of Eq. (3), psychological and occupational stresses maintain positive impact on interpersonal performance. The result of $t$-student indicates that the effects are statistically significant and adjusted R-Square indicates that regression model states that psychological and occupational stresses approximately describe $86 \%$ of the changes on interpersonal performance.

\section{Conclusion}

In this paper, we have presented an empirical investigation to the study the effects of various types of job stress including psychological, occupational as well as organizational stress on women's job performances who worked for some Iranian banking industry. The implementation of Spearman correlation test has indicated that psychological stress could influence on interpersonal performance. In addition, it seems to be psychological stress influences strongly on organizational performance as well as interpersonal performance. In addition, the survey has detected some positive and meaningful relationship between psychological stress and job performance. In our survey, occupational stress influenced positively only on organizational as well as interpersonal performances.

The results of our survey are somewhat consistent with findings of Leung et al. (2011). In their survey, job stress was the antecedent of burnout, while burnout could further forecast physiological stress for construction project managers; job stress was negatively associated only with their task performance; both burnout and physiological stress were negatively associated with their organizational performance; and task performance could lead positively to their interpersonal performance.

Kim et al. (2009) also investigated the moderating impacts of gender and organizational level between role stress and job satisfaction among hotel employees. They reported that the effect of role stress on job satisfaction was substantially stronger for female employees and supervisory employees than male employees and non-supervisory employees. Rivera-Torres et al. (2013) investigated the effects of job stress across gender by studying the relative importance of emotional and intellectual demands and social support in women. They reported that applying the Job Demands, Control and Support technique in function of the gender could contribute to a bigger understanding of how to reduce the levels of job stress in men and women, helping the design of more effective policies in this area.

\section{Acknowledgement}

The authors would like to thank the anonymous referees for constructive comments on earlier version of this paper.

\section{References}

Al-Kahtani, N. S., \& Saad, N. (2013). Job burnout as a function of demographical variables: What do Saudi Arabia banking employees reflect?. Far East Journal of Psychology and Business, 12(2), 12-25.

Arzu, C. A. (2011). Studying the relationship between employees' occupational burnout levels and satisfaction of life: A research in private banks. African Journal of Business Management, 5(16), 6825-6838.

Bashir, U., \& Ramay, M. I. (2010). Impact of stress on employees' job performance a study on banking sector of Pakistan. International Journal of Marketing Studies, 2(1), 122-126. 
Chou, L. P., Li, C. Y., \& Hu, S. C. (2014). Job stress and burnout in hospital employees: comparisons of different medical professions in a regional hospital in Taiwan. BMJ open, 4(2), e004185.

Jamal, M. (2011). Job stress, job performance and organizational commitment in a multinational company: An empirical study in two countries. International Journal of Business and Social Science, 2(20), 20-29.

Khattak, J. K., Khan, M. A., Haq, A. U., Arif, M., \& Minhas, A. A. (2011). Occupational stress and burnout in Pakistans banking sector. African Journal of Business Management, 5(3), 810-817.

Khan, S. N., \& Zafar, S. (2013). Exploring the causes and consequences of job burnout in a developing country. Journal of Basic and Applied Scientific Research, 3(5), 212-227.

Kim, B. P., Murrmann, S. K., \& Lee, G. (2009). Moderating effects of gender and organizational level between role stress and job satisfaction among hotel employees. International Journal of Hospitality Management, 28(4), 612-619.

Leung, M. Y., Chan, Y. S. I., \& Dongyu, C. (2011). Structural linear relationships between job stress, burnout, physiological stress, and performance of construction project managers. Engineering, Construction and Architectural Management, 18(3), 312-328.

Maslach, C., \& Jackson, S. E. (1981). The measurement of experienced burnout. Journal of Organizational Behavior, 2(2), 99-113.

Rahman, H. (2013). Job stress-employees performance and health: A study on commercial bank in Bangladesh. Global Journal of Management And Business Research, 13(4).

Rivera-Torres, P., Araque-Padilla, R. A., \& Montero-Simó, M. J. (2013). Job stress across gender: the importance of emotional and intellectual demands and social support in women. International journal of environmental research and public health, 10(1), 375-389. 